\title{
Preparation and Characterization of Alumina Nanoparticles in Deionized Water Using Laser Ablation Technique
}

\author{
Veeradate Piriyawong, ${ }^{1,2}$ Voranuch Thongpool, ${ }^{1}$ \\ Piyapong Asanithi, ${ }^{1}$ and Pichet Limsuwan ${ }^{1,2}$ \\ ${ }^{1}$ Applied Nanotechnology Laboratory (ANT Lab), Department of Physics, \\ King Mongkut's University of Technology Thonburi, Bangkok 10140, Thailand \\ ${ }^{2}$ Thailand Center of Excellence in Physics, CHE, Ministry of Education, Bangkok 10400, Thailand
}

Correspondence should be addressed to Veeradate Piriyawong, changphysics@hotmail.com and Pichet Limsuwan, opticslaser@yahoo.com

Received 9 August 2012; Accepted 23 October 2012

Academic Editor: Jian Wei

Copyright (C) 2012 Veeradate Piriyawong et al. This is an open access article distributed under the Creative Commons Attribution License, which permits unrestricted use, distribution, and reproduction in any medium, provided the original work is properly cited.

$\mathrm{Al}_{2} \mathrm{O}_{3}$ nanoparticles were synthesized using laser ablation of an aluminum (Al) target in deionized water. Nd:YAG laser, emitted the light at a wavelength of $1064 \mathrm{~nm}$, was used as a light source. The laser ablation was carried out at different energies of 1, 3, and $5 \mathrm{~J}$. The structure of ablated $\mathrm{Al}$ particles suspended in deionized water was investigated using X-ray diffraction (XRD). The XRD patterns revealed that the ablated $\mathrm{Al}$ particles transformed into $\gamma-\mathrm{Al}_{2} \mathrm{O}_{3}$. The morphology of nanoparticles was investigated by field emission scanning electron microscopy (FE-SEM). The FE-SEM images showed that most of the nanoparticles obtained from all the ablated laser energies have spherical shape with a particle size of less than $100 \mathrm{~nm}$. Furthermore, it was observed that the particle size increased with increasing the laser energy. The absorption spectra of $\mathrm{Al}_{2} \mathrm{O}_{3}$ nanoparticles suspended in deionized water were recorded at room temperature using UV-visible spectroscopy. The absorption spectra show a strong peak at $210 \mathrm{~nm}$ arising from the presence of $\mathrm{Al}_{2} \mathrm{O}_{3}$ nanoparticles. The results on absorption spectra are in good agreement with those investigated by XRD which confirmed the formation of $\mathrm{Al}_{2} \mathrm{O}_{3}$ nanoparticles during the laser ablation of $\mathrm{Al}$ target in deionized water.

\section{Introduction}

Metal oxide nanoparticles have been extensively developed in the past decades. They have been widely used in many applications such as catalysts, sensors, semiconductors, medical science, capacitors, and batteries [1-6]. Among them, aluminum oxide $\left(\mathrm{Al}_{2} \mathrm{O}_{3}\right)$ and its compounds have long been known for more than a century, for example, aluminum oxide hydroxide $(\mathrm{AlOOH})$ and aluminum trihydroxide $\left(\mathrm{Al}(\mathrm{OH})_{3}\right)$.

$\mathrm{Al}_{2} \mathrm{O}_{3}$ or alumina generally refers to corundum. It is a white oxide. Alumina has several phases such as gamma, delta, theta, and alpha. However, the alpha alumina phase is the most thermodynamically stable phase. In general, alumina has many interesting properties, for example high hardness, high stability, high insulation, and transparency [7]. Alumina is also widely used in the fire retard, catalyst, insulator, surface protective coating, and composite materials [8-12].

$\mathrm{Al}_{2} \mathrm{O}_{3}$ nanoparticles can be synthesized by many techniques including ball milling, sol-gel, pyrolysis, sputtering, hydrothermal, and laser ablation [13-18]. Among them, the laser ablation is a widely used technique for the synthesis of nanoparticles since it can be synthesized in gas, vacuum or liquid. This technique offers several advantages such as rapid and high purity process compared with other methods [19]. Furthermore, nanoparticles prepared by the laser ablation of materials in liquid are easier to be collected than those of in gas atmosphere.

In the recent years, $\mathrm{Al}_{2} \mathrm{O}_{3}$ nanoparticles were synthesized in liquid using a short pulse laser with the pulse width in the range of nanosecond [20-22]. Furthermore, Al target was used as a starting material for laser ablation in those works. Therefore, in this study we reported the synthesis 


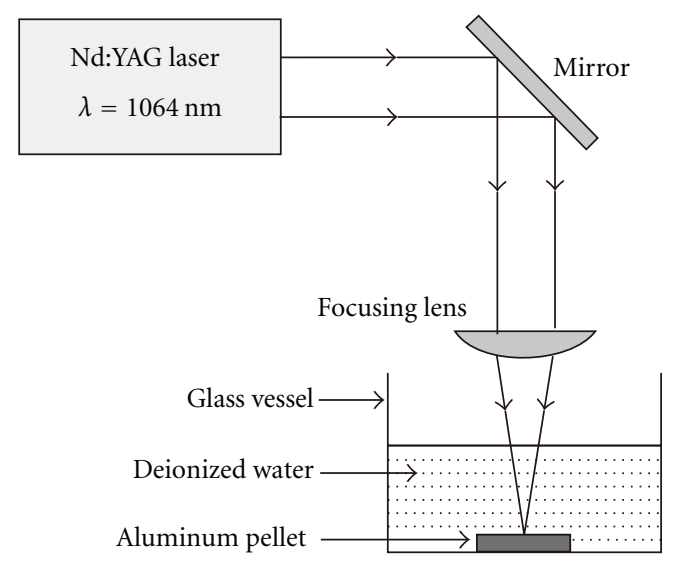

FIgURE 1: Experimental setup for synthesizing $\mathrm{Al}_{2} \mathrm{O}_{3}$ nanoparticles by laser ablation of $\mathrm{Al}$ in deionized water.

of $\mathrm{Al}_{2} \mathrm{O}_{3}$ from $\mathrm{Al}$ powders using laser ablation in deionized water with a long pulsed Nd:YAG laser. The laser pulse widths adopted in this work were $2.5,6$, and $9.5 \mathrm{~ms}$ to obtain the output laser energies of 1,3 , and $5 \mathrm{~J}$, respectively. The particle size and morphology of synthesized nanoparticles obtained at different laser energies were investigated by field emission scanning electron microscopy (FE-SEM). The optical property of synthesized nanoparticles was carried out using UV-visible spectroscopy. The structure of the synthesized nanoparticles was investigated using X-ray diffraction (XRD) technique.

\section{Experimental Setup}

2.1. Material Preparation for Laser Ablation. Aluminum powder with purity of $99.99 \%$ (American Elements) and an average particle size of $35 \mu \mathrm{m}$ were pressed in a stainless steel mold by a hydraulic with a pressure of 100 bars to obtain the aluminum pellet with a diameter of $15 \mathrm{~mm}$ and $5 \mathrm{~mm}$ thick. The aluminum pellet was used as a target for laser ablation. The experimental setup of the laser ablation is shown in Figure 1. The aluminum pellet was placed at the bottom of a glass vessel with a diameter of $30 \mathrm{~mm}$ and $50 \mathrm{~mm}$ in height. Deionized water with a volume approximately of $10 \mathrm{~mL}$ was poured into the vessel until its level was approximately $5 \mathrm{~mm}$ above the target. The Nd:YAG (Miyachi, ML-2331B) that emitted the laser light at a wavelength of $1064 \mathrm{~nm}$ was used for the laser ablation. The laser ablation was carried out at different laser energies of 1,3 , and $5 \mathrm{~J}$ with a repetition rate of $2 \mathrm{~Hz}$. The laser beam was focused by a $50 \mathrm{~mm}$ focallength lens onto the aluminum pellet. For each energy of laser ablation, the aluminum target was ablated with 5,000 pulses for the total time of about $40 \mathrm{~min}$. After the laser ablation, the $\mathrm{Al}_{2} \mathrm{O}_{3}$ particles suspended in deionized water was obtained.

2.2. Characterization. After the laser ablation of $\mathrm{Al}$ target in deionized water was carried out, the Al particles suspended in deionized water were characterized to confirm that they transformed into $\mathrm{Al}_{2} \mathrm{O}_{3}$. The ablated $\mathrm{Al}$ particles suspended

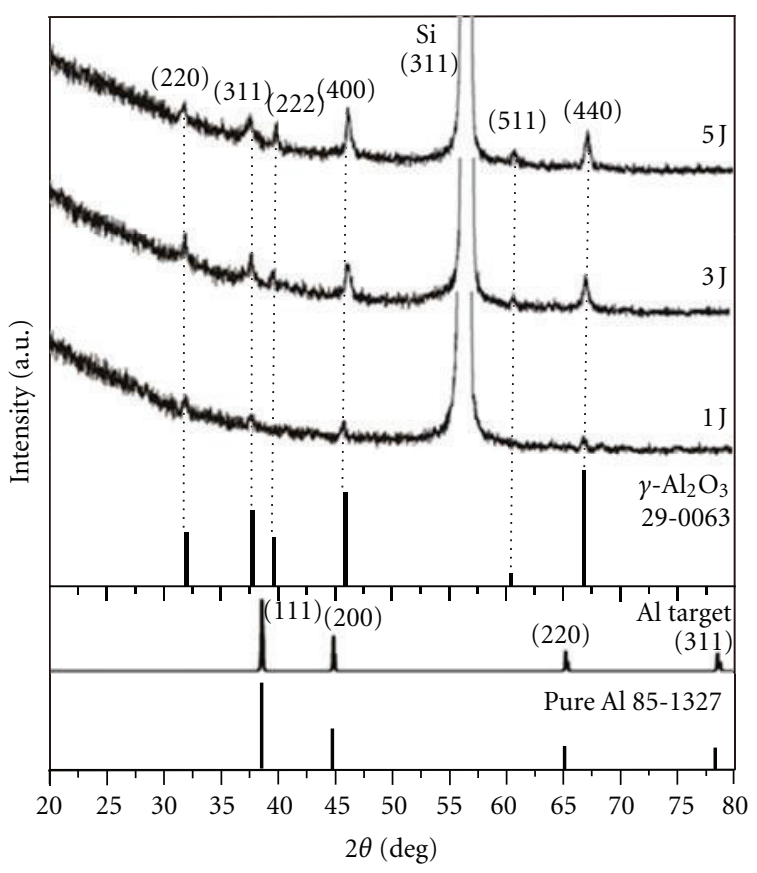

FIGURE 2: XRD patterns of pure $\mathrm{Al}$ and $\mathrm{Al}_{2} \mathrm{O}_{3}$ nanoparticles synthesized from laser energies of 1,3 , and $5 \mathrm{~J}$.

in deionized water were used for the optical measurement. The optical absorption spectra were recorded at room temperature using a UV-Vis spectrophotometer (JASCO, V570). Then, the liquid sample was dropped on silicon wafers and dried in an oven at $40^{\circ} \mathrm{C}$ for $4 \mathrm{~h}$. The dried-particles sample on silicon substrates was used for investigating the structure and morphology. The structure of particles was investigated using X-ray diffraction (PANalytical, X'Pert Pro) with $\mathrm{CuK}_{\alpha}$ radiation and a pattern recorded at grazing incidence angle $\left(3^{\circ}\right)$ in the $2 \theta$ range of $20^{\circ}-80^{\circ}$ with a scan step of 0.02 in a scan time of $5 \mathrm{~s}$. The morphology of particles was investigated using field emission scanning electron microscopy (Hitachi, S4700).

\section{Results and Discussion}

3.1. The Structure of Ablated Particles. The structure of ablated particles was investigated by XRD measurement. To identify the structural difference between ablated particles and $\mathrm{Al}$, the XRD measurement for $\mathrm{Al}$ target was also carried out. Figure 2 shows the XRD patterns of Al target and particles synthesized from laser energies of 1,3 , and $5 \mathrm{~J}$. The observed peaks in Figure 2 could be indexed based on pure $\mathrm{Al}$ and $\gamma-\mathrm{Al}_{2} \mathrm{O}_{3}$ phase in Joint Committee on Powder Diffraction Standard-International Center for Diffraction Data (JCPDS-ICDD) Card nos. 85-1327 and 29-0063, respectively. It is seen from the XRD spectra that all particles obtained from laser ablation with different laser energies are $\gamma-\mathrm{Al}_{2} \mathrm{O}_{3}$. This confirms that $\mathrm{Al}$ transformed into $\gamma-\mathrm{Al}_{2} \mathrm{O}_{3}$ after the ablation in deionized water. Moreover, it is clearly observed that the intensity of XRD peaks increased with increasing 


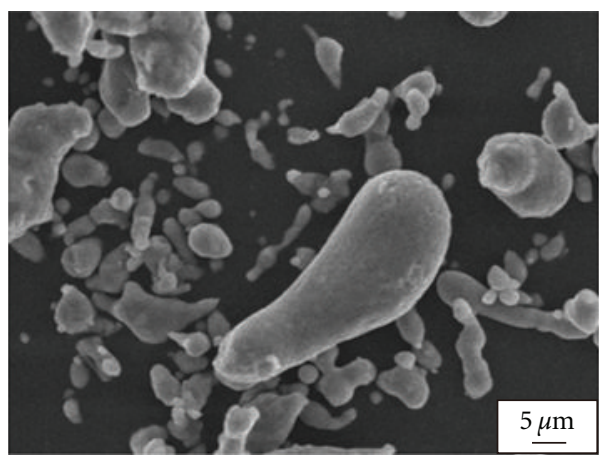

(a)

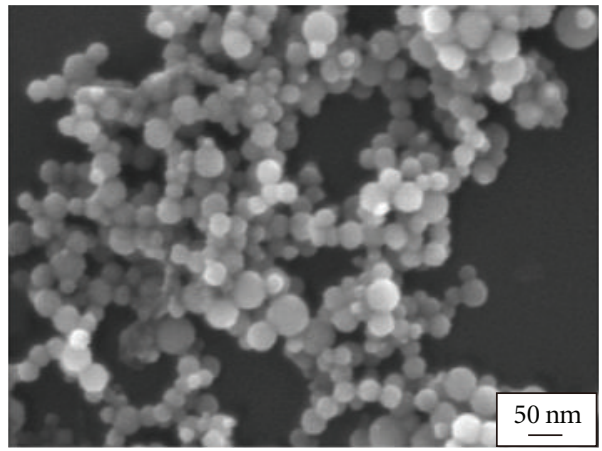

(c)

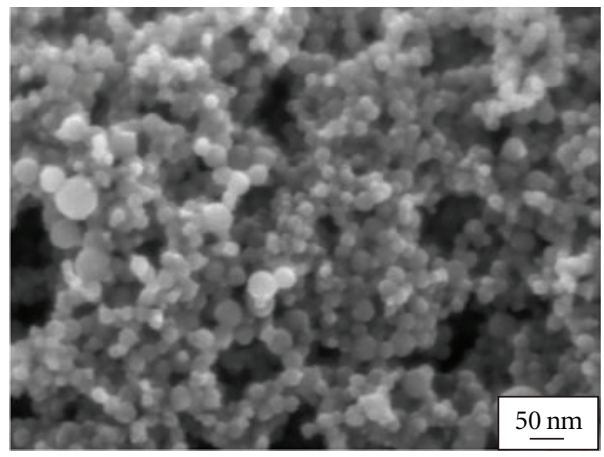

(b)

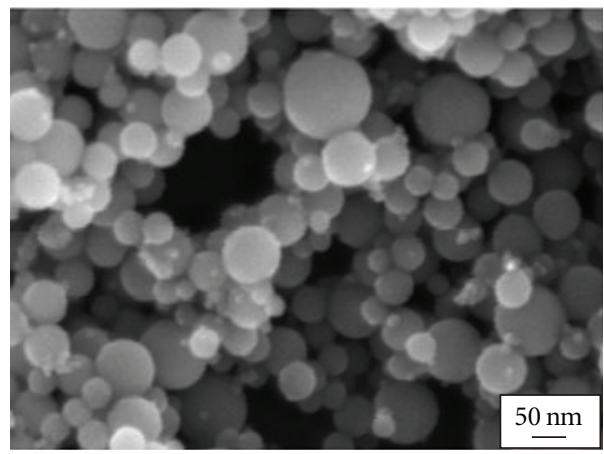

(d)

Figure 3: FE-SEM images of (a) aluminum powder, and $\mathrm{Al}_{2} \mathrm{O}_{3}$ nanoparticles at different laser energies of (b) $1 \mathrm{~J}$, (c) $3 \mathrm{~J}$, and (d) $5 \mathrm{~J}$.

laser energy. This might lead to the conclusion that the particle concentration, suspended in deionized water, obtained from a laser energy of $5 \mathrm{~J}$ is higher than those of 1 and $3 \mathrm{~J}$.

It should be pointed out that the phase transitions in aluminum oxide occur in the following order [23]:

$$
\gamma-\mathrm{Al}_{2} \mathrm{O}_{3} \longrightarrow \delta-\mathrm{Al}_{2} \mathrm{O}_{3} \longrightarrow \theta-\mathrm{Al}_{2} \mathrm{O}_{3} \longrightarrow \alpha-\mathrm{Al}_{2} \mathrm{O}_{3} .
$$

Since $\gamma-\mathrm{Al}_{2} \mathrm{O}_{3}$ occurs at the lowest temperature compared with those of another phases, the most likely phase of $\mathrm{Al}_{2} \mathrm{O}_{3}$ to be formed after laser ablation of $\mathrm{Al}$ target in deionized water is $\gamma-\mathrm{Al}_{2} \mathrm{O}_{3}$.

3.2. Morphology of $\mathrm{Al}_{2} \mathrm{O}_{3}$ Nanoparticles. The morphology of dried $\mathrm{Al}_{2} \mathrm{O}_{3}$ nanoparticle samples obtained from the laser ablation of aluminum pellet in deionized water at different energies was investigated using field emission scanning electron microscopy. For comparison, the morphology of aluminum powder was also investigated. Figure 3(a) shows the FE-SEM image of the aluminum powder used as the target. It revealed that the morphology of the aluminum was a nonspherical shape with the size in the range of $1-35 \mu \mathrm{m}$. Figures $3(\mathrm{~b})-3(\mathrm{~d})$ show the FE-SEM images of the $\mathrm{Al}_{2} \mathrm{O}_{3}$ nanoparticles synthesized in deionized water with different laser energies of 1,3 , and $5 \mathrm{~J}$, respectively. It is clearly observed that the morphology of the synthesized $\mathrm{Al}_{2} \mathrm{O}_{3}$ nanoparticles is mostly spherical shape. These results are in good agreement with those previously reported in reference [20-22].

The particle size distribution of the $\mathrm{Al}_{2} \mathrm{O}_{3}$ nanoparticles could be obtained by measuring the size of total particles of
TABle 1: Average particle size of $\mathrm{Al}_{2} \mathrm{O}_{3}$ nanoparticles.

\begin{tabular}{lcc}
\hline Laser energy $(\mathrm{J} /$ pulse $)$ & Laser fluence $\left(\mathrm{J} / \mathrm{cm}^{2}\right)$ & Average size $(\mathrm{nm})$ \\
\hline 1 & 3333 & 26 \\
3 & 10000 & 38 \\
5 & 16667 & 53 \\
\hline
\end{tabular}

about 200 particles in the FE-SEM image using the Image J program. The plots of the particle size distribution of the $\mathrm{Al}_{2} \mathrm{O}_{3}$ nanoparticles are shown in Figure 4. The average particle size of the $\mathrm{Al}_{2} \mathrm{O}_{3}$ nanoparticles is summarized in Table 1. As seen in Figure 4, the particle size of the $\mathrm{Al}_{2} \mathrm{O}_{3}$ nanoparticles synthesized in deionized water with laser energies of 1,3 , and $5 \mathrm{~J}$ are ranged from 10 to 60,10 to 70 , and 10 to $110 \mathrm{~nm}$, respectively. The average particle size of the $\mathrm{Al}_{2} \mathrm{O}_{3}$ nanoparticles as given in Table 1 showed that the smallest particle size of the $\mathrm{Al}_{2} \mathrm{O}_{3}$ nanoparticles was obtained from a laser energy of $1 \mathrm{~J}$ and found to be $26 \mathrm{~nm}$ with the narrow particle size distribution in the range of $10-60 \mathrm{~nm}$. It is seen that the higher laser energy seemed to promote more collisions between the vapour atoms/ions, to coalesce within the ablated plume and eventually to form larger particles.

It should be noted that the spot size of the laser at the target surface is $0.03 \mathrm{~mm}^{2}$. Hence, the laser fluence $\left(\mathrm{J} / \mathrm{cm}^{2}\right)$ can be determined and the results are also given in Table 1.

3.3. Optical Property of $\mathrm{Al}_{2} \mathrm{O}_{3}$ Nanoparticle in Deionized Water. Figure 5 shows the opacity of deionized water after 


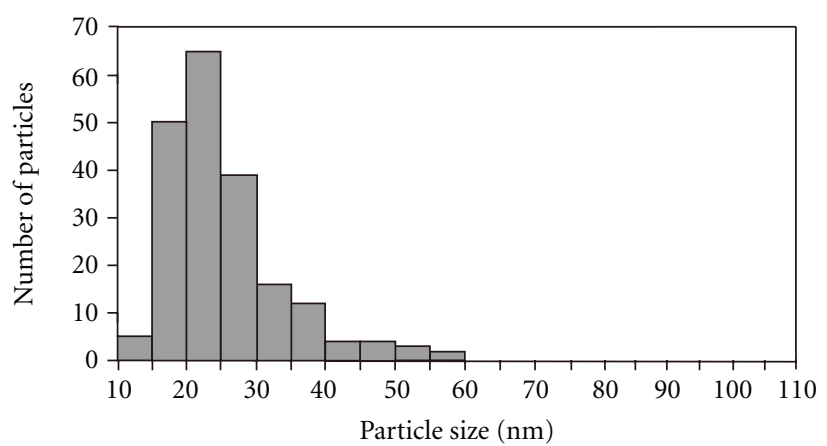

(a)

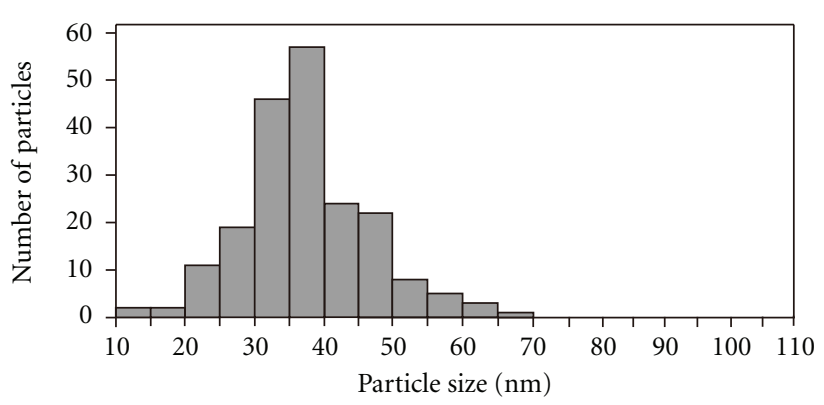

(b)

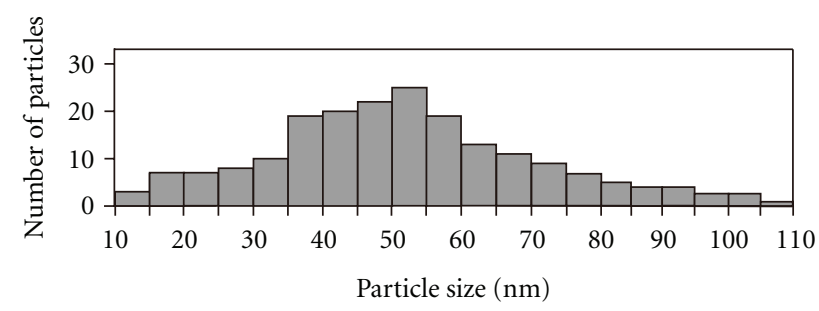

(c)

FIgURE 4: Plots of particle size distribution of $\mathrm{Al}_{2} \mathrm{O}_{3}$ nanoparticles at different energies (a) $1 \mathrm{~J}$, (b) $3 \mathrm{~J}$, and (c) $5 \mathrm{~J}$.

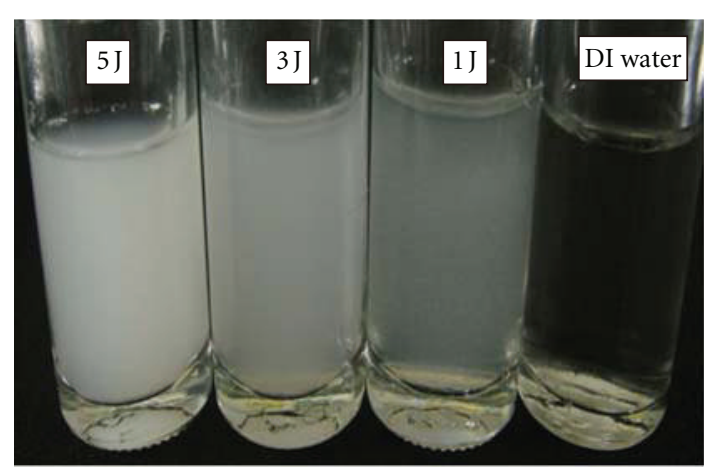

FIGURe 5: Photographs showing the opacity of deionized water before and after laser ablation at different laser energies of 1,3 , and $5 \mathrm{~J}$.

the laser ablation of $\mathrm{Al}$ with different laser energies. It is clearly observed that the opacity of deionized water increases with increasing laser energy. It can be concluded that the opacity of deionized water is proportional to the number of $\mathrm{Al}_{2} \mathrm{O}_{3}$ nanoparticles suspended in deionized water. Hence, the $\mathrm{Al}_{2} \mathrm{O}_{3}$ nanoparticles obtained from a laser energy of $5 \mathrm{~J}$ are higher than those obtained from 3 and $1 \mathrm{~J}$.

Figure 6 shows the absorption spectra of deionized water with suspended $\mathrm{Al}_{2} \mathrm{O}_{3}$ nanoparticles obtained from laser energies of 1,3 , and $5 \mathrm{~J}$. A strong absorption peak at $210 \mathrm{~nm}$ is clearly observed which confirms the presence of $\mathrm{Al}_{2} \mathrm{O}_{3}$ nanoparticles in deionized water $[24,25]$ and not those of aluminum [26-28]. As seen in Figure 6, the difference of absorbance is due to the different $\mathrm{Al}_{2} \mathrm{O}_{3}$ nanoparticle concentrations suspended in deionized water.

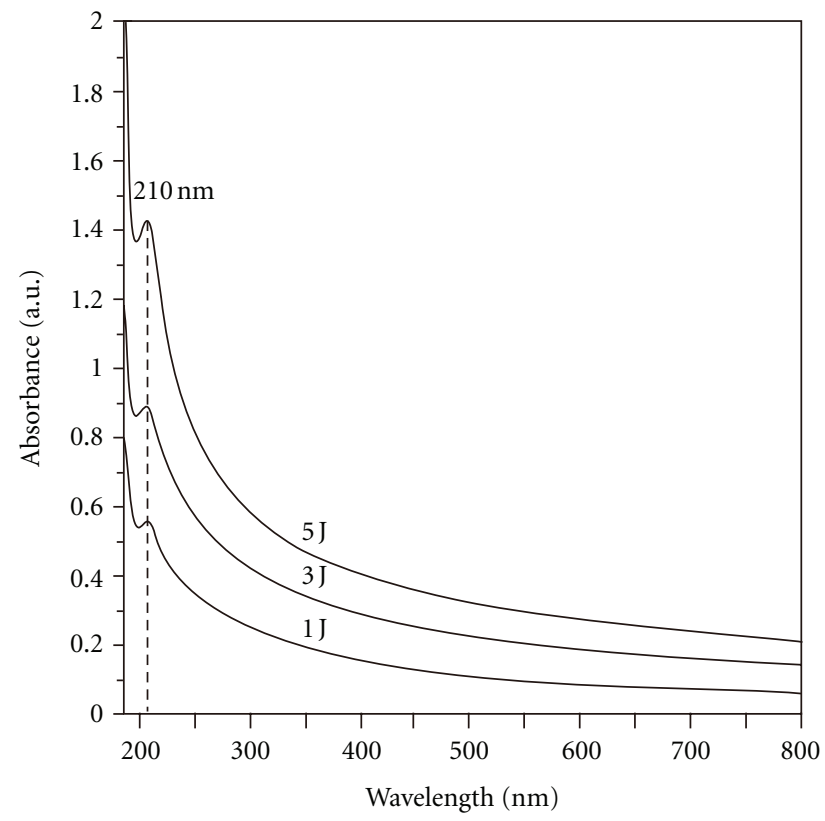

Figure 6: Absorption spectra in deionized water with suspended $\mathrm{Al}_{2} \mathrm{O}_{3}$ nanoparticles prepared from different laser energies of 1,3 , and $5 \mathrm{~J}$.

To confirm the dependence of the absorbance on the $\mathrm{Al}_{2} \mathrm{O}_{3}$ nanoparticle concentration, all the samples of deionized water with suspended $\mathrm{Al}_{2} \mathrm{O}_{3}$ nanoparticles were diluted with deionized water to obtain different water concentrations of $\mathrm{C} / 2, \mathrm{C} / 4, \mathrm{C} / 8$, and $\mathrm{C} / 16$, where $\mathrm{C}$ is the initial concentration. All the diluted deionized water samples were used 


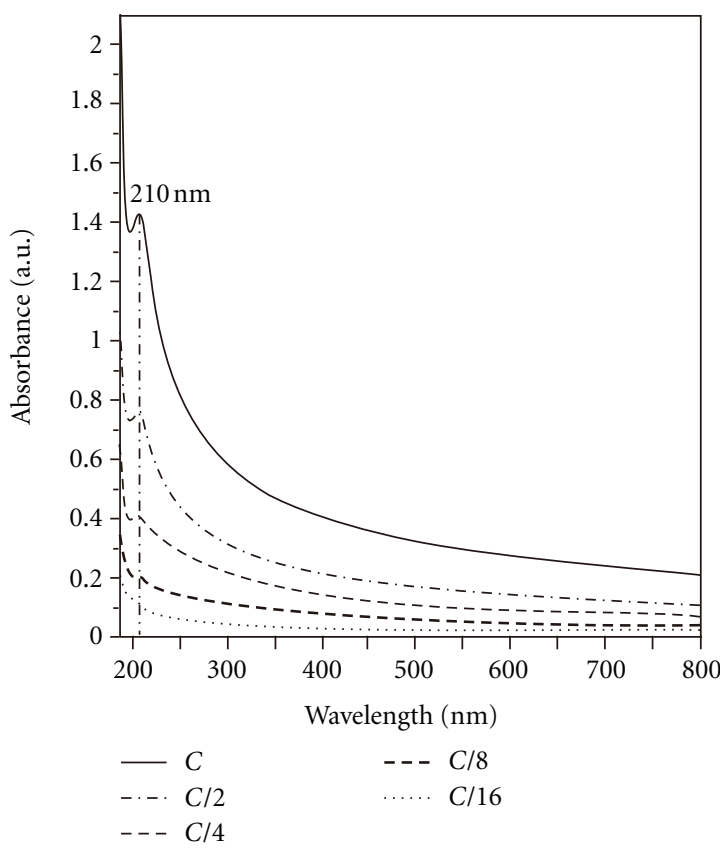

(a)

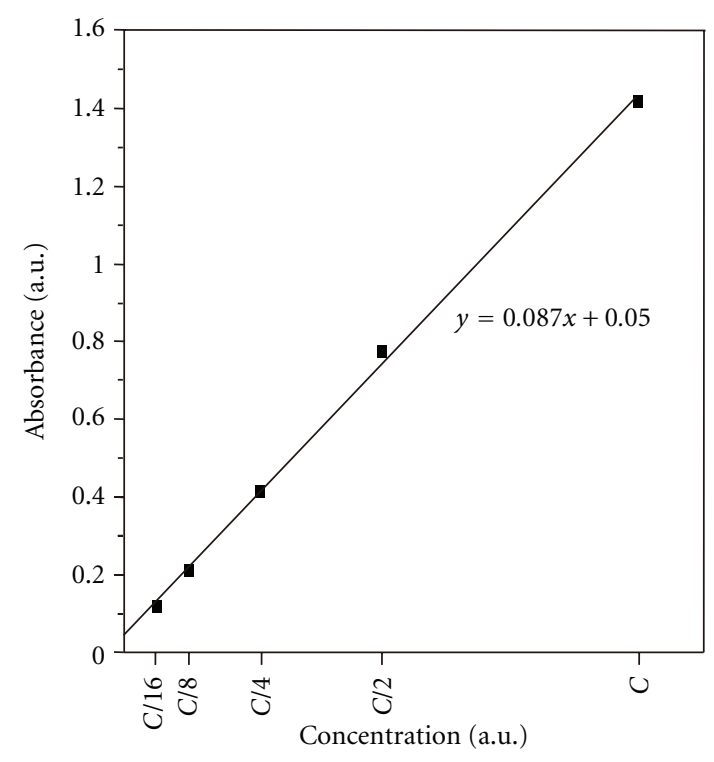

(b)

FIGURE 7: (a) The typical absorption spectra of deionized water with different suspended $\mathrm{Al}_{2} \mathrm{O}_{3}$ nanoparticle concentrations for the laser ablation at an energy of $5 \mathrm{~J}$ and (b) linear relationship between the absorbance and the concentration at wavelength $210 \mathrm{~nm}$.

for absorption measurements. Figure 7(a) shows the typical absorption spectra of the deionized water with different $\mathrm{Al}_{2} \mathrm{O}_{3}$ nanoparticle concentrations obtained from a laser energy of $5 \mathrm{~J}$. It is seen that the absorbance decreases with decreasing concentration. The plot between $\mathrm{Al}_{2} \mathrm{O}_{3}$ nanoparticle concentration and absorbance is shown in Figure 7(b). Figure $7(\mathrm{~b})$ shows that the absorbance depends linearly on the $\mathrm{Al}_{2} \mathrm{O}_{3}$ nanoparticle concentration. Similar results were also obtained for laser energies of 1 and $3 \mathrm{~J}$.

\section{Conclusion}

We have successfully demonstrated that $\gamma-\mathrm{Al}_{2} \mathrm{O}_{3}$ nanoparticles can be synthesized from $\mathrm{Al}$ powder by pulsed laser ablation in deionized water. $\mathrm{Al}$ powder was pressed to obtain the $\mathrm{Al}$ pellet and used as a target for laser ablation. The advantage of using compressed $\mathrm{Al}$ powder is that we can sieve the $\mathrm{Al}$ powder to obtain small particle size for starting materials of laser ablation. Therefore, it is easier to obtain $\mathrm{Al}_{2} \mathrm{O}_{3}$ nanoparticles compared with those obtained from laser ablation of Al plate. The effect of laser energy on the particle size was investigated. It was found that $\mathrm{Al}_{2} \mathrm{O}_{3}$ particle size ablated at a low laser energy was smaller than that obtained from high laser energy. However, high laser energy yielded high $\mathrm{Al}_{2} \mathrm{O}_{3}$ concentration than that of low laser energy.

\section{Acknowledgments}

This work had been supported by Thailand Center of Excellent in Physics (ThEP) and King Mongkut's University of
Technology Thonburi under The National Research University Project.

\section{References}

[1] W. Ueda, M. Sadakane, and H. Ogihara, "Nano-structuring of complex metal oxides for catalytic oxidation," Catalysis Today, vol. 132 , no. $1-4$, pp. 2-8, 2008.

[2] T. Gessner, K. Gottfried, R. Hoffmann et al., "Metal oxide gas sensor for high temperature application," Microsystem Technologies, vol. 6, no. 5, pp. 169-174, 2000.

[3] J. H. Kim, E. K. Kim, C. H. Lee, M. S. Song, Y.-H. Kim, and J. Kim, "Electrical properties of metal-oxide semiconductor nano-particle device," Physica E, vol. 26, no. 1-4, pp. 432-435, 2005.

[4] P. D. Pria, "Evolution and new application of the alumina ceramics in joint replacement," European Journal of Orthopaedic Surgery and Traumatology, vol. 17, no. 3, pp. 253-256, 2007.

[5] H. Farsi and F. Gobal, "Theoretical analysis of the performance of a model supercapacitor consisting of metal oxide nanoparticles," Journal of Solid State Electrochemistry, vol. 11, no. 8, pp. 1085-1092, 2007.

[6] A. C. Dillon, A. H. Mahan, R. Deshpande, P. A. Parilla, K. M. Jones, and S.-H. Lee, "Metal oxide nano-particles for improved electrochromic and lithium-ion battery technologies," Thin Solid Films, vol. 516, no. 5, pp. 794-797, 2008.

[7] L. D. Hart, Alumina Chemicals: Science and Technology Handbook, American Ceramic Society, Columbus, Ohio, USA, 1990.

[8] A. Laachachi, M. Ferriol, M. Cochez, J.-M. Lopez Cuesta, and D. Ruch, "A comparison of the role of boehmite (AlOOH) and alumina $\left(\mathrm{Al}_{2} \mathrm{O}_{3}\right)$ in the thermal stability and flammability 
of poly(methyl methacrylate)," Polymer Degradation and Stability, vol. 94, no. 9, pp. 1373-1378, 2009.

[9] I. Lukić, J. Krstić, D. Jovanović, and D. Skala, "Alumina/silica supported $\mathrm{K}_{2} \mathrm{CO}_{3}$ as a catalyst for biodiesel synthesis from sunflower oil," Bioresource Technology, vol. 100, no. 20, pp. 4690-4696, 2009.

[10] M. Touzin, D. Goeuriot, C. Guerret-Piécourt, D. Juvé, and H. J. Fitting, "alumina based ceramics for high-voltage insulation," Vacuum, vol. 81, pp. 762-765, 2007.

[11] A. Keyvani, M. Saremi, and M. Heydarzadeh Sohi, "Microstructural stability of zirconia-alumina composite coatings during hot corrosion test at $1050^{\circ} \mathrm{C}$," Journal of Alloys and Compounds, vol. 506, no. 1, pp. 103-108, 2010.

[12] R. Lach, K. Haberko, M. M. Bućko, M. Szumera, and G. Grabowski, "Ceramic matrix composites in the alumina/530vol.\% YAG system," Journal of the European Ceramic Society, vol. 31, no. 10, pp. 1889-1895, 2011.

[13] C. B. Reid, J. S. Forrester, H. J. Goodshaw, E. H. Kisi, and G. J. Suaning, "A study in the mechanical milling of alumina powder," Ceramics International, vol. 34, no. 6, pp. 1551-1556, 2008.

[14] F. Mirjalili, M. Hasmaliza, and L. C. Abdullah, "Size-controlled synthesis of nano $\alpha$-alumina particles through the solgel method," Ceramics International, vol. 36, no. 4, pp. 12531257, 2010.

[15] R. Kavitha and V. Jayaram, "Deposition and characterization of alumina films produced by combustion flame pyrolysis," Surface and Coatings Technology, vol. 201, no. 6, pp. 24912499, 2006.

[16] D. H. Trinh, M. Ottosson, M. Collin, I. Reineck, L. Hultman, and $\mathrm{H}$. Högberg, "Nanocomposite $\mathrm{Al}_{2} \mathrm{O}_{3}-\mathrm{ZrO}_{2}$ thin films grown by reactive dual radio-frequency magnetron sputtering," Thin Solid Films, vol. 516, no. 15, pp. 4977-4982, 2008.

[17] L. Qu, C. He, Y. Yang, Y. He, and Z. Liu, "Hydrothermal synthesis of alumina nanotubes templated by anionic surfactant," Materials Letters, vol. 59, no. 29-30, pp. 4034-4037, 2005.

[18] K. Yatsui, T. Yukawa, C. Grigoriu, M. Hirai, and W. Jiang, "Synthesis of ultrafine $\gamma-\mathrm{Al}_{2} \mathrm{O}_{3}$ powders by pulsed laser ablation," Journal of Nanoparticle Research, vol. 2, no. 1, pp. 75-83, 2000.

[19] A. Kruusing, Handbook of Liquids-Assisted Laser Processing, Elsevier, 2008.

[20] Z. Yan, R. Bao, Y. Huang, and D. B. Chrisey, "Hollow particles formed on laser-induced bubbles by excimer laser ablation of Al in liquid," Journal of Physical Chemistry C, vol. 114, no. 26, pp. 11370-11374, 2010.

[21] I. L. Liu, P. Shen, and S. Y. Chen, " $\mathrm{H}^{+}$- and $\mathrm{Al}^{2+}$-codoped $\mathrm{Al}_{2} \mathrm{O}_{3}$ nanoparticles with spinel-type related structures by pulsed laser ablation in water," Journal of Physical Chemistry C, vol. 114, no. 17, pp. 7751-7757, 2010.

[22] B. Kumar and R. K. Thareja, "Synthesis of nanoparticles in laser ablation of aluminum in liquid," Journal of Applied Physics, vol. 108, no. 6, Article ID 064906, 2010.

[23] W. H. Gitzen, Alumina as Ceramic Material, special publication no. 4, American Ceramic Society, 1970.

[24] H. Chang and Y. C. Chang, "Fabrication of $\mathrm{Al}_{2} \mathrm{O}_{3}$ nanofluid by a plasma arc nanoparticles synthesis system," Journal of Materials Processing Technology, vol. 207, no. 1-3, pp. 193-199, 2008.

[25] V. S. Kortov, S. V. Nikiforov, I. I. Milman, and E. V. Moiseykin, "Specific features of luminescence of radiation-colored $\alpha$ $\mathrm{Al}_{2} \mathrm{O}_{3}$ single crystals," Radiation Measurements, vol. 38, no. 4 6, pp. 451-454, 2004.
[26] E. Stratakis, V. Zorba, M. Barberoglou, C. Fotakis, and G. A. Shafeev, "Femtosecond laser writing of nanostructures on bulk Al via its ablation in air and liquids," Applied Surface Science, vol. 255, no. 10, pp. 5346-5350, 2009.

[27] G. Viau, V. Collière, L. M. Lacroix, and G. A. Shafeev, "Internal structure of $\mathrm{Al}$ hollow nanoparticles generated by laser ablation in liquid ethanol," Chemical Physics Letters, vol. 501, no. 4-6, pp. 419-422, 2011.

[28] E. Stratakis, M. Barberoglou, C. Fotakis, G. Viau, C. Garcia, and G. A. Shafeev, "Generation of al nanoparticles via ablation of bulk al in liquids with short laser pulses," Optics Express, vol. 17, no. 15, pp. 12650-12659, 2009. 

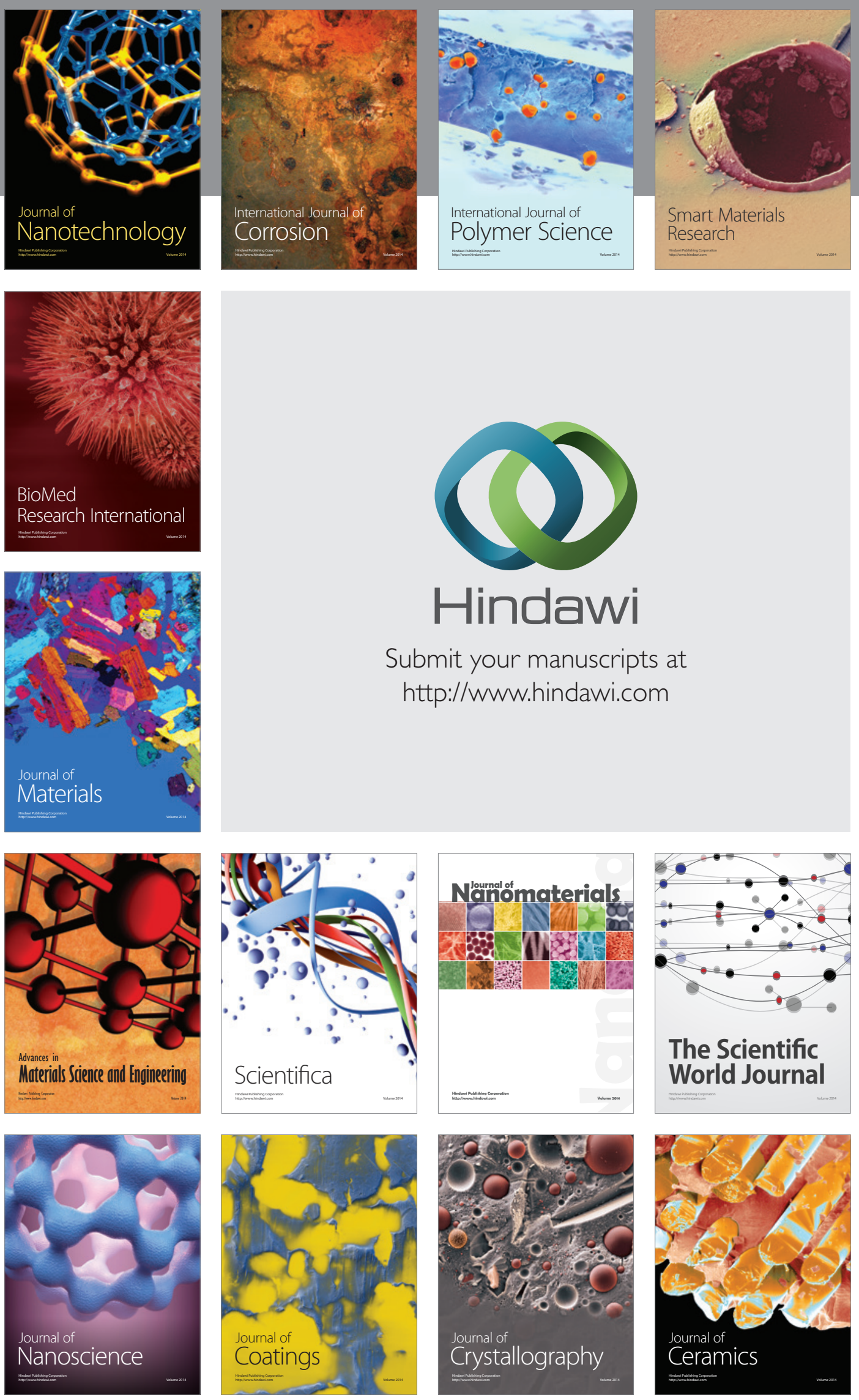

The Scientific World Journal

Submit your manuscripts at

http://www.hindawi.com

\section{World Journal}

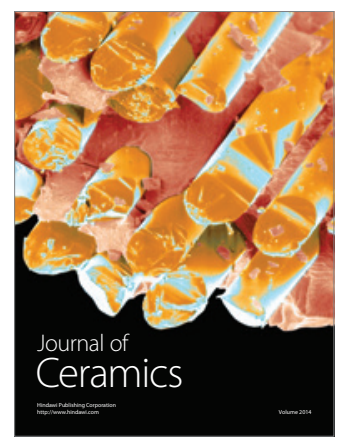

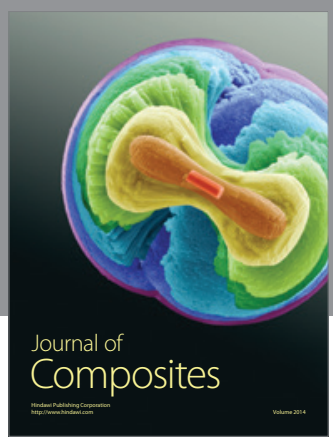
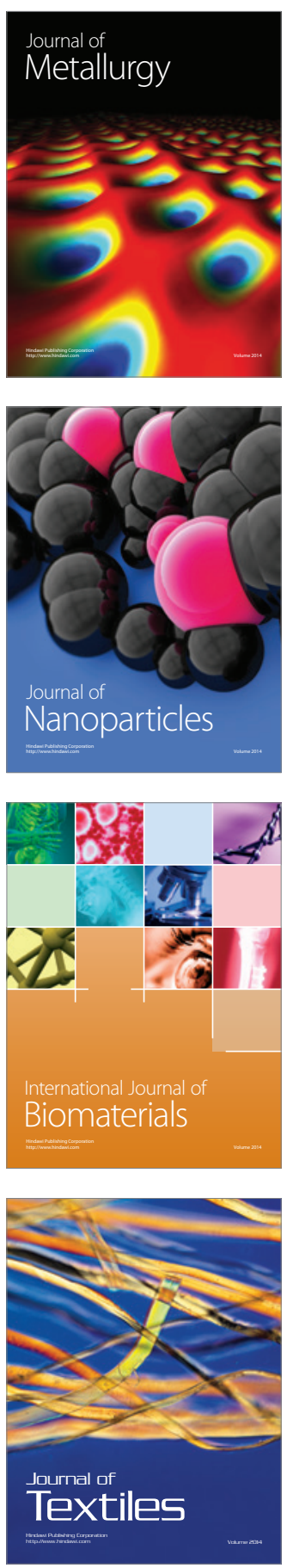